\title{
Covid-19: local implementation of tracing and testing programmes could enable some schools to reopen
}

\author{
Allyson M Pollock professor of public health \\ Faculty of Medical Sciences, The Medical School, Newcastle University, Newcastle upon Tyne NE2 4HH, UK
}

As a public health physician, I am increasingly concerned about the apparent failure to implement fundamental public health measures to tackle the covid-19 outbreak-specifically, community contact tracing, clinical observation, and testing-and about what seems to be one of the knock-on effects of this failure-the blanket closure of schools.

Tracing and clinical observation of contacts, isolation, and quarantine are the classic tools in public health to deal with infectious diseases. ${ }^{1}$ The World Health Organization reports that these have been painstakingly adopted in China in response to covid-19, with a high percentage of identified close contacts completing medical observation ${ }^{2}$; and they have been strongly recommended by WHO for other countries.

We lack data in England-contact tracing seems to have been adopted only initially. Modelling conducted by Keeling and colleagues (the authors of one of the papers published by the government last week), indicates that it would enable the outbreak to be contained. "Aggregating across all individuals and under the optimistic assumption that all the contact tracing can be performed rapidly, we expect contact tracing to reduce the basic reproductive ratio from 3.11 to 0.21 -enabling the outbreak to be contained," they write. "Rapid and effective contact tracing can therefore be highly effective in the early control of covid-19, but places substantial demands on the local public health authorities."

The basic reproductive ratio, $\mathrm{R}_{0}$, is a standard epidemiological construct for understanding the epidemic potential of an infection: the higher the ratio, the more difficult it will be to control its spread. ${ }^{4}$ If $\mathrm{R}_{0}$ is less than 1 , an infected person will on average transmit the infection to less than one other person, so the epidemic potential is critically reduced. Based on this modelling, if contact tracing is not being rigorously conducted now, the possibility of critically reducing the epidemic will be missed. The paper by Keeling and colleagues taken together with the New England Complex Systems Initiative critique ${ }^{5}$ raise serious questions about the validity of the model from Imperial College's covid-19 response team, ${ }^{6}$ the apocalyptic numbers of which were used by the Westminster government to justify its approach.

I am concerned that contact tracing, clinical observation, appropriate testing, quarantine, and isolation have not been exhaustively carried out before taking the blanket decision to close all schools. I have sent the opposition spokespeople for health at Westminster some suggested parliamentary questions that my colleague Peter Roderick and I have drafted.

Notably, many areas in Scotland and Wales and parts of England have low numbers of cases, so at this stage taking an area approach to vigorous and meticulous contact tracing and clinical observation and testing should make it possible to contain the disease-in Singapore, the BBC reports that the army has been called in to help with this. ${ }^{8}$ This would, in time, with other measures, allow local areas to safely consider reopening schools on a school by school basis and thus uphold each child's right to education.

One of the major differences in this outbreak is that it is being centrally managed rather than centrally coordinated, with insufficient foot soldiers on the ground. The pandemic is at different stages around the country. Local authorities and directors of public health in England cannot tailor responses to the local situation and are subject to central policy decisions. My colleagues in public health in local authorities say that they have received very little information. This, combined with the devastating cuts to community based communicable disease control and the changes wrought by the Health and Social Care Act 2012 (which carved out public health from health services in England and then further fragmented communicable disease control by removing it to Public Health England) have created a perfect storm.

I urge the Scottish and Welsh governments to immediately institute a massive centrally coordinated contact tracing and clinical observation and testing programme that is based locally. They should discuss with local authorities, health boards, trade unions, public health and communicable disease control experts, and schools, colleges, and universities how this tried and tested classic approach would, with other measures, enable the blanket 
school closure decision to be modified in favour of a local strategy.

\section{Competing interests: None declared.}

1 Tanne JH, Hayasaki E, Zastrow M, Pulla P, Smith P, Rada AG. Covid-19: how doctors and healthcare systems are tackling coronavirus worldwide. BMJ 2020;368:m1090. 10.1136/bmj.m1090 32188598

2 World Health Organization. Report of the WHO-China joint mission on coronavirus disease 2019 (covid-19). 16-24 February 2020. https://www.who.int/docs/default-source/ coronaviruse/who-china-joint-mission-on-covid-19-final-report.pdf

3 Keeling MJ, Hollingsworth D, Read JM. The efficacy of contact tracing for the containment of the 2019 novel coronavirus (COVID-19). medRxiv 20023036 [Preprint]. 2020. https://doi.org/10.1101/2020.02.14.20023036
4 Heffernan JM, Smith RJ, Wahl LM. Perspectives on the basic reproductive ratio. J R Soc Interface 2005;2:281-93. 10.1098/rsif.2005.0042. 16849186

5 Shen C, Taleb NN, Bar-Yam Y. Review of Ferguson et al "Impact of non-pharmaceutical interventions .. "New England Complex Systems Institute. 17 Mar 2020. https://necsi. edu/review-of-ferguson-et-al-impact-of-non-pharmaceutical-interventions

6 Ferguson NM, Laydon D, Nedjati-Gilani G, et al, On behalf of the Imperial College COVID-19 Response Team. Impact of non-pharmaceutical interventions (NPIs) to reduce covid-19 mortality and healthcare d . media/imperial-college/medicine/sph/ide/gida-fellowships/Imperial-College-COVID19-NPI-
modelling-16-03-2020.pdf

7 Pollock A. Covid-19 and public health reforms. https://www.allysonpollock.com/?page_ id $=2903$

8 Vaswani K. Coronavirus: The detectives racing to contain the virus in Singapore. BBC News 19 March 2020. https://www.bbc.co.uk/news/world-asia-51866102

Published by the BMJ Publishing Group Limited. For permission to use (where not already granted under a licence) please go to http://group.bmj.com/group/rights-licensing/ permissions 